\title{
DISTRIBUIÇÃO DE CONTEÚDOS E APRENDIZAGEM ON-LINE EDUCATIONAL CONTENT SYNDICATION AND ONLINE LEARNING
}

\author{
Suzana de Souza Gutierrez*
}

\begin{abstract}
Resumo
A distribuição de conteúdo por meio de tecnologias como o RSS e o Atom é uma tendência que vem crescendo rapidamente na internet. Publicações de todos os tipos vêm juntar-se a milhares de weblogs, criando uma nova forma de distribuir informação. Este artigo tem como objetivo dar uma visão geral sobre a distribuição de conteúdo, seu desenvolvimento e suas tecnologias, procurando focalizar as suas possibilidades de utilização na educação.
\end{abstract}

Palavras-chave: aprendizagem on-line, distribuição de conteúdo, educação, internet, RSS.

\begin{abstract}
Content syndication by means of technologies such as RSS and Atom are growing quickly on the internet. Publications of all kinds come to join thousands of weblogs, creating a new way for information distribution. This article has as objective to give an overview on content syndication, its development and its technologies, trying to focus on its possibilities of use in education.
\end{abstract}

Keywords: content syndication, education, internet, online learning, RSS.

\footnotetext{
* Professora e Engenheira, Mestre em Educação PPGEDU/UFRGS. Professora do Colégio Militar de Porto Alegre. Pesquisadora do TRAMSE/UFRGS. ssguti@terra.com.br 


\section{Introdução}

Há alguns meses venho cultivando um novo hábito e ampliando um outro já mais antigo. Antes de ler e responder e-mails, abro o Sharpreader $^{1}$ e dedico uma meia hora a leitura de notícias nos canais que subscrevi.

No espaço de tempo que daria apenas para passar os olhos num jornal tradicional, tenho a possibilidade de consultar o sumário de mais de cinqüenta sítios, $w_{e b l o g} s^{2}$ e jornais on-line de todos os tipos, com a opção de aprofundar os conteúdos que me despertarem maior interesse.

Isso só é possível graças ao desenvolvimento e a disseminação de tecnologias de agregação e distribuição de conteúdo. Esta tecnologia, mais conhecida como RSS (Rich Site Summary ou Really Simple Syndication) ${ }^{3}$, foi desenvolvida originalmente para uso no navegador Netscape ${ }^{4}$ e, hoje, é adotada em publicações de notícias, weblogs e outros sítios. Sua popularidade deve-se a agilidade que confere a leitura dos conteúdos por dispensar o acesso ao sítio e, também, a relativa facilidade de sua inserção numa página ou weblog. Um outro motivo importante, é que é possível implantar e utilizar esta tecnologia sem nenhum custo, tanto para leitura, quanto para disponibilização de um canal.

Este tema tem recebido minha atenção de dois anos para cá, quando iniciei meu mestrado, recentemente concluído. Na parte empírica de minha investigação desenvolvi um projeto de uma comunidade de weblogs reunida em torno de um weblog colaborativo. Estes weblogs de pesquisadores ligados ao $\mathrm{TRAMSE}^{5}$ deram origem a projetos que extrapolaram as paredes do PPGEDU, chegando a outros cursos da UFRGS.

Neste projeto, que tem o nome de Projeto [zaptlogs] $]^{6}$, utilizei os protocolos de agregação de conteúdo de forma a acessar os conteúdos dos weblogs individuais e de projetos, facilitando sobremaneira a leitura dos conteúdos postados e o acesso aos comentários. Todo este processo está descrito na minha dissertação Mapeando caminhos de autoria e autonomia: a inserção das tecnologias educacionais informatizadas no trabalho de educadores que cooperam em comunidades de pesquisadores, onde, nas conclusões, saliento a importância dos weblogs e da agregação de conteúdo na realização dos objetivos propostos.

Em fevereiro último, fui procurada pela reportagem do jornal Estado de São Paulo para falar das minhas experiências com o uso do RSS na educação. Na matéria, 
que foi publicada no caderno de Informática, apenas dois educadores foram entrevistados e, isso, mostra como é recente a descoberta das possibilidades dos protocolos de agregação de conteúdo pela educação. Porém, a tecnologia desenvolve-se aceleradamente e, hoje, quando elaboro este texto, já é possível receber notícias via RSS em telefones móveis.

\section{Colher, agregar e distribuir conteúdo}

Os protocolos ou códigos que fazem o recolhimento, a agregação e a distribuição de conteúdo são documentos XML (Extensible Markup Language) ${ }^{7}$. São documentos que capturam conteúdo (texto, imagem, som) de um sítio, reúnem este conteúdo num aplicativo agregador e o entregam para serem visibilizados em aplicativos leitores como o Sharpreader ou distribuídos (sindicados) para publicação. O endereço (URL Uniform Resource Locator) deste documento, que é semelhante a um endereço normal de um sítio, é adicionado como um canal no aplicativo leitor e, imediatamente, 'puxa' os conteúdos do site.

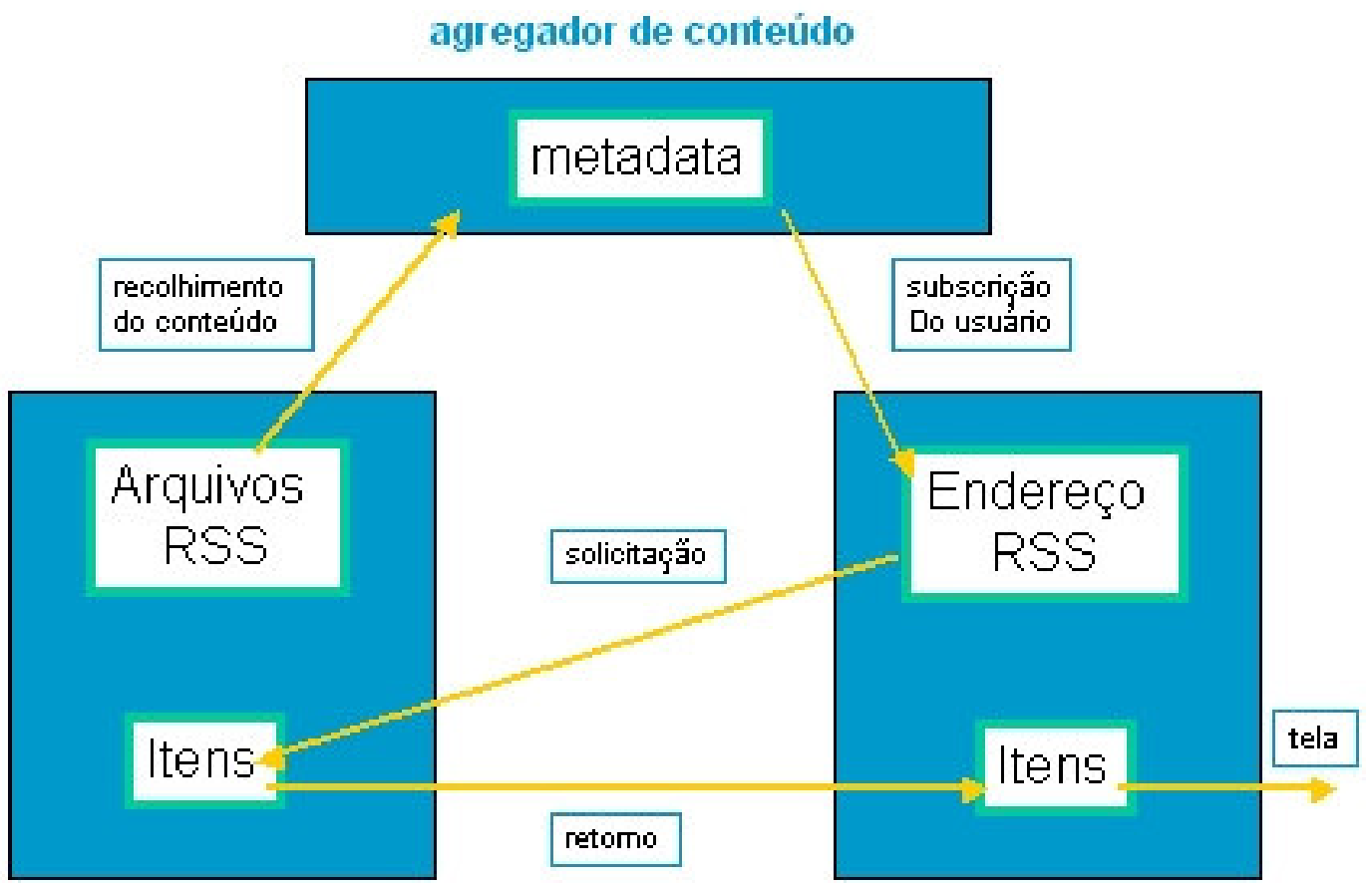

provedor de conteúdo

leitor/ visualizador

Figura 1 - arquitetura da rede $R S S$ 
O fato das informações serem em $X M L$ e não numa linguagem de publicação como o HTML (HyperText Markup Language) ${ }^{8}$, faz com que o RSS e o Atom possam ser explorados sobre diversas formas: em leitores de navegadores, em PDAs (Personal Digital Assistant $)^{9}$, telefones celulares e clientes de e-mail, utilizando, até, áudio e vídeo.

Assim, por meio do RSS/Atom podem ser lidos conteúdos de sítios, de weblogs, de listas de discussão públicas etc.. Podem ser indexados e acessados recursos educacionais de forma distribuída, formando uma rede de conteúdo, com maior abrangência e menor custo do que as formas que hoje vêm sendo utilizadas.

Qualquer adição ou alteração no conteúdo distribuído do sítio será agregada e mostrada nos leitores de RSS/Atom. Sítios dinâmicos com conteúdos muito variáveis como os de últimas notícias, previsão do tempo, indicadores econômicos, programações culturais e esportivas e agendas diversas serão, facilmente, acompanhados por meio do RSS/Atom. Da mesma forma em que podemos ler o horóscopo ou a charge do dia, podemos acessar as imagens de câmeras de segurança. Por outro lado, o RSS/Atom auxilia, também, o acompanhamento de sítios com poucas, mas importantes, modificações, pois o leitor de notícias sinalizará qualquer alteração.

Combinando o formato weblog com o RSS/Atom, o que a maioria dos serviços de weblogs já proporciona, pode-se criar repositórios de recursos e objetos educacionais, verdadeiras bibliotecas digitais, que mostrarão, por meio dos agregadores, as últimas atualizações.

Nesta perspectiva, utilizando RSS/Atom e os leitores de notícias, acessamos a internet nos nossos termos, pois a escolha dos conteúdos fica em nossas mãos. Diferentemente do correio eletrônico, onde estamos sujeitos a receber correspondência não solicitada, propagandas e vírus, num leitor de notícias adicionamos (ou subscrevemos) os canais que queremos ler e excluímos o que não nos interessar mais. Além disso, nos leitores de notícias podem ser criadas pastas que organizem os endereços RSS/Atom por tema ou conteúdo.

Na figura 2, que mostra a janela de um leitor de conteúdo, é possível ver, na coluna da esquerda todos os sítios escolhidos e adicionados, que podem ser lidos na coluna da direita. Na parte superior da coluna da direita, são listados os tópicos postados, na parte inferior, lê-se, em formato texto puro, parte ou todo o texto do post. Clicar duas vezes num tópico fará com que na janela inferior apareça o sítio, conforme ele é exposto na web. É possível, também, abrir em outra janela os assuntos que 
interessarem, entrando na página propriamente dita. Os tópicos podem ser guardados ou deletados e existe a possibilidade de filtrá-los por assunto e/ou por data.

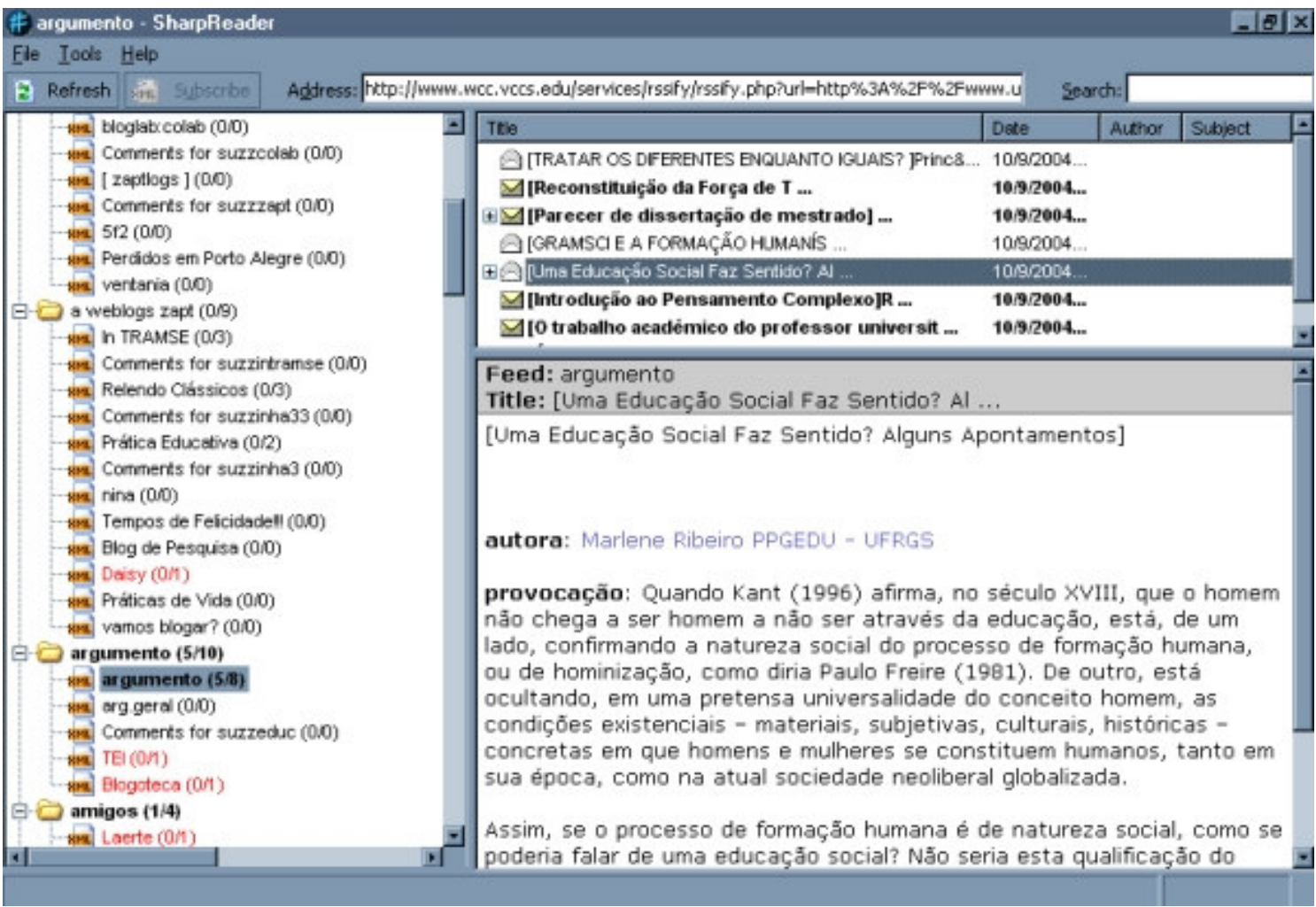

Figura 2 - A janela do Sharpreader da autora.

Atualmente, encontra-se em expansão a distribuição de conteúdo via RSS/Atom, com a adesão (ou rendição) de grandes veículos de comunicação, como, por exemplo, o NY Times e a revista Wired, que já se deram conta das possibilidades e popularidade deste formato. No Brasil, a Folha Online ${ }^{10}$ é um dos poucos jornais eletrônicos que distribuem seu conteúdo via $R S S$.

Em relação aos aplicativos leitores de conteúdo é interessante salientar as diferenças de funcionamento entre os diversos tipos. Os semelhantes ao Sharpreader, são aplicativos que necessitam ser instalados no computador do usuário.

Existem aplicativos baseados na web, por exemplo, o Bloglines, que é um serviço gratuito, onde, mediante um cadastro, o usuário pode adicionar, manejar e ler os sítios que subscreve e, ainda, compartilhar suas leituras por meio de um blog e de um endereço $R S S^{11}$. A vantagem em relação ao primeiro tipo é que o usuário pode ter acesso às suas subscrições em qualquer computador, em qualquer lugar. 
Uma outra forma de receber conteúdo RSS/Atom é por meio do correio eletrônico, usando os canais de notícia, necessitando, porém, instalar um aplicativo que faz a ligação do correio com o conteúdo sindicado.

\section{RSS e Educação}

Um objeto de aprendizagem pode ser conceituado como sendo todo o objeto que é utilizado como meio de ensino/aprendizagem. Um cartaz, uma maquete. uma canção, um ato teatral, uma apostila, um filme, um livro, um jornal, uma página na web, podem ser objetos de aprendizagem.

A maioria destes objetos de aprendizagem pode ser reutilizada, modificada ou não e servir para outros objetivos que não os originais. Em muitas escolas existe aquele famoso depósito, nem sempre muito organizado, onde se guardam (às vezes, sepultam) objetos que fizeram parte de aulas e projetos. Um depósito de onde se recuperam estes objetos para reutilização, modificação, até que o desgaste inviabilize novas transformações e utilizações.

Neste aspecto, os objetos digitais, têm algumas vantagens sobre os objetos materiais. Podem ser copiados e reproduzidos, gravados em suportes diversos, tendo uma vida mais longa. Por outro lado, se não adequadamente organizados, acondicionados e catalogados, podem ficar perdidos entre outros arquivos digitais.

A possibilidade de copiar um objeto digital de aprendizagem aliada à possibilidade de editá-lo e modificá-lo, faz com que possam ser criados novos objetos de aprendizagem sem que os originais se percam. Por exemplo, uma apresentação feita num editor para projeção multimídia, pode ser reutilizada mantendo-se a estrutura básica, esquema de cores, transição, animação e modificando-se conteúdos e imagens.

Uma webquest ${ }^{12}$ criada para a aprendizagem de um determinado tema, pode ser reutilizada, mantendo a organização geral das páginas e modificando o conteúdo para trabalhar o mesmo tema com alunos de outro nível.

Assim como notícias e outras informações podem ser indexadas e distribuídas por meio do RSS/Atom, o mesmo pode ser feito em relação a conteúdos educacionais e objetos de aprendizagem. Segundo Stephen Downes (2002), o modelo de gerenciamento de conteúdo educacional por RSS é diferente do modelo LCMS (Learning Content Management System $)^{13}$. O modelo LCMS utiliza aplicativos que acondicionam os conteúdos e os disponibilizam, na forma de pacotes, em repositórios ou bibliotecas. Para 
estruturação de todo este processo, é necessário domínio de conhecimentos técnicos específicos e adoção de aplicativos, o que pode tornar o projeto mais oneroso.

No caso do RSS, não existe esta centralização, o conteúdo permanece distribuído pela internet e basta um simples aplicativo de leitura para acessá-lo. Como resultado, temos um projeto de desenvolvimento mais fácil e com menor custo. A acessibilidade ao conteúdo, também, é facilitada e ampliada.

Neste sentido, aproximando a tecnologia do RSS da concepção de conteúdo educacional em objetos de aprendizagem podemos entrever grandes possibilidades para a educação no uso destes meios.

Alguns exemplos do uso dos protocolos de agregação e de distribuição de conteúdo, desenvolvidos usando recursos existentes na web e/ou pertencentes a projetos desenvolvidos colaborativamente:

\subsection{Projeto Blogoteca}

Um exemplo do uso do RSS é o projeto Blogoteca ${ }^{14}$, que é um modelo para criação de um espaço de agregação de objetos educacionais por meio de weblogs e RSS. Foi idealizado tendo como referência escolas ou instituições que disponham de recursos tecnológicos mínimos. Poucos computadores conectados a internet permitem construir e manter uma blogoteca, não sendo necessários servidores, domínios ou aplicativos proprietários. Optou-se por serviços gratuitos de weblogs e RSS e por utilizar agregadores, editores e outros aplicativos também gratuitos e, de preferência, de código aberto.

O que batizamos de blogoteca é um sistema de weblogs interligados, partindo de um ambiente geral e tantos blogs quantas forem as categorias, os assuntos ou os temas em que se subdividirão os objetos educacionais.

Uma blogoteca tem um tema geral bem abrangente, como, por exemplo, ensino médio, e categorias dentro deste tema, como, por exemplo, matemática, literatura, aprendizagem, saúde. Um outro exemplo, para não configurar uma abordagem disciplinar, seria um tema geral como Saúde e categorias como: políticas, prevenção, nutrição, saneamento. 
Nesta perspectiva, podemos notar que as blogotecas podem (e devem) se interlinkar formando uma rede ampla de objetos de aprendizagem e recursos educacionais.

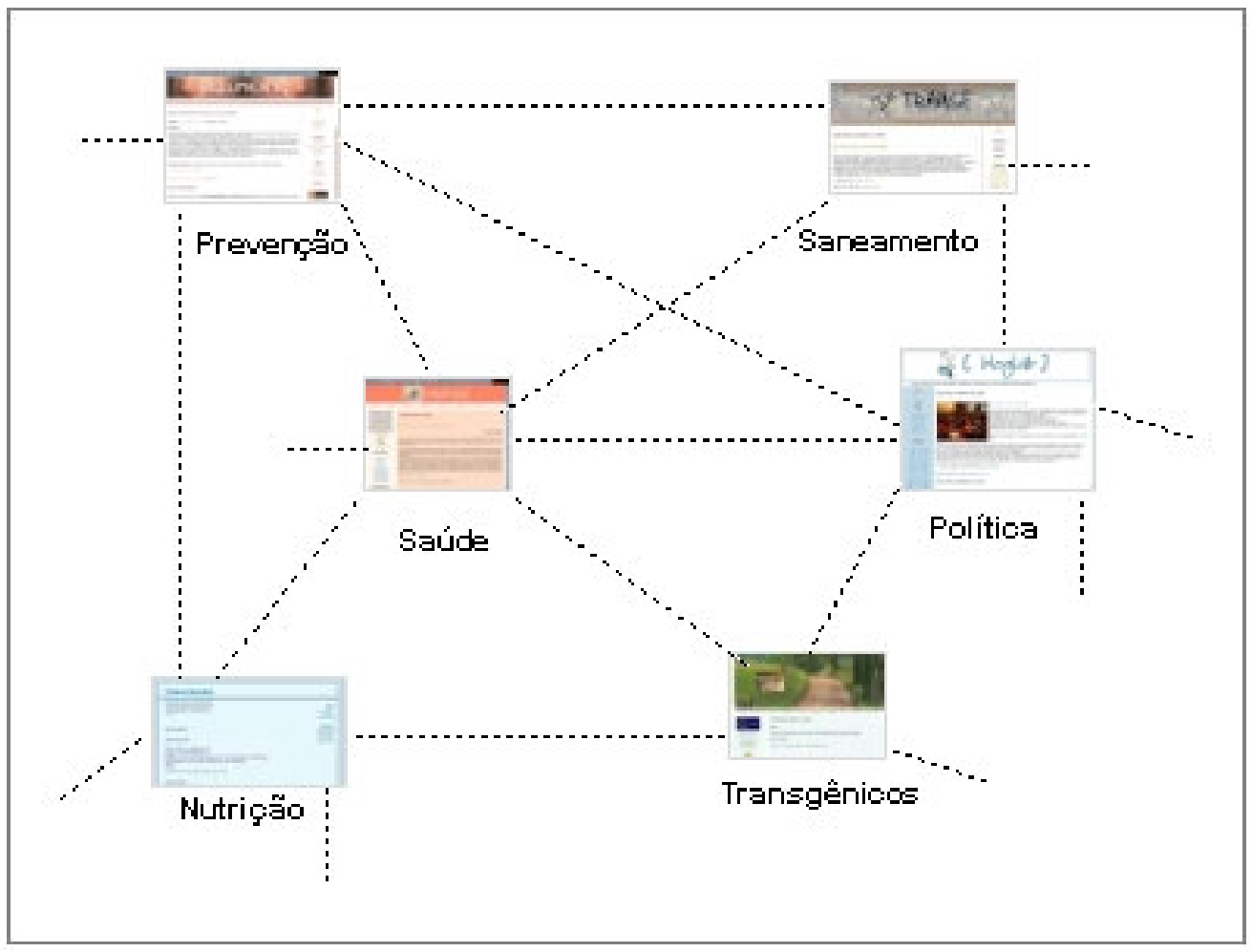

Figura 3 - este exemplo mostra um recorte de uma rede de blogotecas interligadas.

Todos os blogs componentes de uma blogoteca terão seu conteúdo distribuído por RSS e serão interlinkados. Um objeto educacional será sempre postado pelo menos em dois blogs: no principal e numa ou mais categorias. Além disso, pode ser linkado em outras blogotecas.

Por exemplo: um artigo sobre tecnologias educacionais informatizadas utilizadas no ensino de enfermagem, poderá estar postado em blogotecas e/ou categorias de Educação, Enfermagem, Saúde, Tecnologia. Neste exemplo, poderia se considerar que Enfermagem é uma blogoteca que tem uma categoria chamada Saúde que, por sua vez é, também, uma blogoteca. O mesmo artigo poderia estar indexado numa blogoteca de Educação, numa categoria de Tecnologia.

\subsection{Argumento}


Argumento foi o nome escolhido para o projeto de uma revista eletrônica construída por meio de weblogs interligados. Penso, e nisso me ajuda Paulo Freire (1983) que não é no fechamento e nem na pesquisa escondida, que se transforma o mundo. É neste contexto que pensei o Argumento.

Nós educadores, alunos e professores, construímos, ao longo das nossas práticas, textos, reflexões, apresentações, palestras, imagens, etc. - trabalhos de todos os tipos que, na maioria dos casos, ficam empoeirando numa pasta ou esquecidos num arquivo no computador. Saber isolado, inativo, morto. O blog Argumento é o ambiente geral do projeto que tem como objetivo resgatar e agregar toda a produção dos educadores ligados ao TRAMSE.

O projeto, ainda em fase inicial, tem como meta expandir-se e agregar, além dos textos e resenhas, objetos de aprendizagem produzidos no núcleo de pesquisa. Os diversos blogs são rssficados podendo ser lidos em agregadores de notícias ou até recebidos por e-mail.

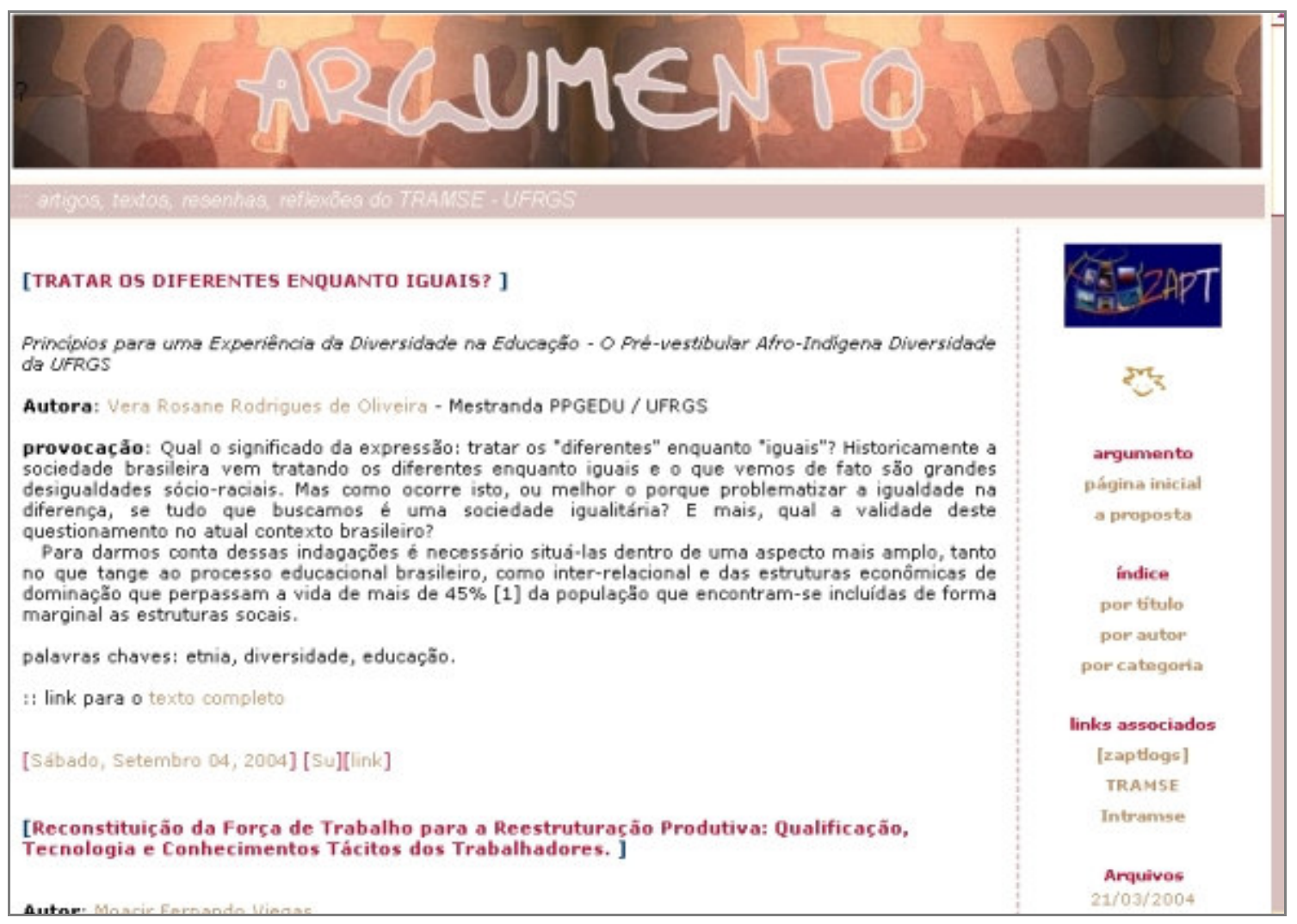

Figura 4 - Argumento, página inicial. 
A página inicial mostra o resumo dos últimos textos com links para os textos completos. Os links fixos remetem ao índice que lista os textos por categoria, por nome do autor e por título. As categorias, até o presente momento são: educação, movimentos sociais, trabalho e resenhas. Em cada texto, é colocado o nome do autor, uma breve identificação e uma forma de contato. No final de cada texto encontra-se um link onde podem ser adicionados comentários. Além disso, os resumos e textos são arquivados por data de postagem, permanecendo à disposição.

Não existem normas de publicação e nem comissão editorial para avaliar textos. A publicação é a critério do autor e não tem periodicidade definida. Sugere-se que os textos não tenham mais que vinte páginas ou que sejam divididos em textos menores, por razões técnicas de velocidade de exibição da página.

A avaliação fica por conta dos leitores e de seus comentários. A idéia é a de que os textos estimulem o debate e a crítica, admitindo-se publicar textos que respondam/critiquem outros textos. Pode, em princípio, parecer anárquico e pouco confiável, porém é uma idéia que põe à prova a coragem dos educadores em expor suas construções teóricas, mesmo imperfeitas, mas abertas à colaboração e ao diálogo.

Neste sentido, a proposta subverte o formato dos textos acadêmicos, burla o engessamento das publicações tradicionais e questiona as autorias fechadas, a produção restrita aos pares e sinaliza na direção de um conhecimento distribuído, solidário, autoria compartilhada, socialmente construído na polifonia de muitas vozes.

Em relação ao papel do protocolo de agregação, o Argumento usa RSS e atom. Os endereços para subscrição ficam na página inicial.

Os leitores têm acesso ao conteúdo visitando o weblog em seu endereço (URL), que é o modo tradicional de acessar conteúdo na web. Outra forma de acessar o conteúdo do Argumento é recebendo o sumário dos artigos postados por meio de um leitor de RSS/atom. Esta segunda opção, que mostra a grande contribuição que os protocolos de agregação de conteúdo trazem ao projeto, daria ao leitor a possibilidade de receber imediatamente qualquer texto adicionado à revista, podendo ler e comentar os de sua escolha, sem necessitar acessar o weblog de forma independente. A revista chega ao leitor ao invés de o leitor procurar a revista.

No Argumento, além do conteúdo, podem ser sindicados os comentários para serem lidos no agregador, também. Na figura 2, pode ser visualizado um post da revista, como ele é mostrado pelo leitor de conteúdo. 
O Argumento foi construído usando tecnologia gratuita encontrada na web, para os blogs, para o RSS e para o sistema de comentários. Está hospedado no espaço do TRAMSE, mas poderia ter hospedagem gratuita do Blogger que é o serviço de weblogs. Assim, seu projeto pode ser reconstruído em lugares que disponham de poucos recursos tecnológicos, sendo suficiente um computador com acesso à internet.

\subsection{Outros usos dos protocolos de agregação de conteúdo em Educação}

Outra forma de utilizar as possibilidades da agregação/distribuição de conteúdo é na pesquisa na internet. Existem já serviços que acionam sistemas de busca como o Google e disponibilizam um canal de pesquisa que entrega seus resultados por meio de um endereço $R S S$, que pode ser lido em agregadores de notícias. O serviço gratuito da Indigo Steam chama-se Google Alert ${ }^{15}$ e, mediante cadastro, o usuário pode registrar até cinco pesquisas diferentes, cujos resultados serão fornecidos pelo endereço $R S S$ sempre que houver alteração. Desta forma, o sistema de busca permanece ininterruptamente pesquisando a web em busca das informações solicitadas.

Podemos pensar, ainda, em socializar nossos $\operatorname{links}^{16}$ favoritos com nossos alunos ou incentivar que eles colecionem links e comentários sobre determinados assuntos, de forma aberta, simples e colaborativa. Isso pode ser feito usando um aplicativo web que armazena os links, os distribui em categorias e fornece endereços $R S S$ para o conteúdo geral e para cada categoria.

Um destes aplicativos é o del.icio.us ${ }^{17}$, onde podemos nos cadastrar e começar a colecionar, categorizar, arquivar e socializar nossos links favoritos. Agregando ainda mais o conteúdo, o del.icio.us mostra, na sua página inicial, os últimos links adicionados por seus usuários e os classifica segundo as categorias escolhidas. Está se tornando comum consultar o conteúdo acessado de outros usuários com interesses em comum, subscrevendo-os via RSS e, além disso, pode ser estratégico subscrever os favoritos de experts de determinados temas.

Para citar um exemplo conhecido, Howard Rheingold, conhecido autor de Comunidade Virtual e Smartmobs, socializa seus achados na web em $<$ http://del.icio.us/hrheingold $>$. Para quem pesquisa sobre comunidades virtuais é interessante subscrever esta sua categoria.

É importante, ainda, salientar que todas estas ferramentas e meios acabam por se relacionar colaborativamente. Por exemplo, no Sharpreader, clicando um item do menu 
podemos postar o conteúdo selecionado em nosso weblog ou adicionar um link diretamente ao del.icio.us. Além disso, a grande notícia é que todos estes meios são gratuitos e acessíveis com poucos recursos tecnológicos.

\section{Considerações Finais}

Há quem diga que as tecnologias de agregação e distribuição de conteúdo são o futuro ou a nova face da web. Outros predizem que, em breve, elas estarão integrando a maioria dos meios e ambientes que utilizarmos. O certo é que ainda vamos nos encontrar muito com os termos XML, sindicação, RSS, Atom, agregadores etc.. Possivelmente, alguns deles venham a fazer parte do cotidiano de cada vez mais pessoas, da mesma forma como o e-mail.

Em relação à educação, as possibilidades são muitas, mas resta ainda um longo caminho a ser trilhado para que esta e outras tecnologias emergentes possam ser parte integrante dos processos e práticas educativas.

\section{Notas do texto}

${ }^{1}$ Os endereços de todos os sítios citados estão nas referências. Sharpreader é o nome de um aplicativo leitor de conteúdo. Mais informações em <http://www.sharpreader.net>.

${ }^{2}$ Weblog ou blog é um tipo de publicação dinâmica na web.

${ }^{3}$ Existem diferentes protocolos para a agregação de conteúdo, por exemplo, o Atom, que é um formato aberto semelhante ao RSS,

${ }^{4}$ Sobre isso, ver o artigo What is RSS? de Mark Pilgrim, publicado em dez/2002 e disponível em $<$ http://www.xml.com/pub/a/2002/12/18/dive-into-xml.html >.

5 TRAMSE - Núcleo de Estudos, Experiências e Pesquisa em Trabalho, Movimentos Sociais, Saúde e Educação - do Programa de Pós-Graduação em Educação (PPGEDU) da Universidade Federal do Rio Grande do Sul (UFRGS).

6 O projeto [zaptlogs] tem este nome porque é um subprojeto do projeto integrado ZAPT que, por sua vez, quer dizer Zona de Apoio e Pesquisa em Tecnologia. O ZAPT é um projeto do TRAMSE.

${ }^{7} X M L$ é uma metalinguagem, que é usada para definir outras linguagens de programação.

8 HTML significa linguagem de marcação de hipertexto e é uma das linguagens para construção de páginas na web.

9 PDA é um computador de dimensões reduzidas, um pouco maior que um telefone celular.

10 A Folha Online é a versão digital do jornal Folha de São Paulo. Sobre RSS?Atom, consultar a reportagem de 26/08/2004 no caderno de Informática: Acompanhe notícias da Folha Online no formato $R S S$, disponível em <http://www1.folha.uol.com.br/folha/informatica/ult124u16829.shtml>

11 No endereço <http://www.bloglines.com/public/suzzinha/> podem ser acessadas as leituras da autora.

${ }^{12}$ Webquests são formas de trabalhar com atividades cooperativas e investigativas utilizando páginas na web.

${ }_{13}$ Um Learning Content Management System é um sistema de gerenciamento de conteúdo de aprendizagem.

${ }_{14}$ O protótipo pode ser visualizado em <http://www.ufrgs.br/tramse/bt/>.

15 Mais informações em <http://www.google.com/alerts/>.

16 Um link é uma ligação. Uma porção de texto ou imagem configurada de tal forma que, ao ser clicada com o mouse, abre uma outra página ou remete para um outro lugar da mesma página.

$17 \mathrm{Em}<\mathrm{http}: / /$ del.icio.us/suzzinha>, a autora disponibiliza seus links favoritos, que podem, também serem recebidos via $R S S$ subscrevendo <http://del.icio.us/rss/suzzinha>. 


\section{Referências}

[ZAPTLOGS] weblog Porto Alegre: Suzana Gutierrez, 2004. Disponível em $<$ http://planeta.terra.com.br/educacao/Gutierrez/blogs/zapt/>. Acesso em 10 set 2004.

ARGUMENTO weblog Porto Alegre: TRAMSE-UFRGS, 2004. Disponível em $<$ http://www.ufrgs.br/tramse/argos/>. Acesso em 10 set 2004.

BLOGGER homepage São Francisco, CA: Pyra Labs, 2004. Disponível em $<$ http://www.blogger.com/>. Acesso em 10 set 2004.

BLOGLINES. homepage. Redwood City, CA: Trustic Inc., 2004. Disponível em $<$ http://www.bloglines.com/>. Acesso em 10 set 2004.

BLOGOTECA weblog Porto Alegre: TRAMSE-UFRGS, 2004. Disponível em $<$ http://www.ufrgs.br/tramse/bt/>. Acesso em 10 set 2004.

DEL.ICIO.US. homepage. Pittsburgh, PA: Joshua Schachter, 2004. Disponível em $<$ http://del.icio.us/>. Acesso em 10 set 2004.

DOWNES, Stephen. An Introduction to RSS for Educational Designers. Ottawa, Ontário: Sthepen's Web, 2002. Disponível em <http://www.downes.ca/files/RSS_Educ.htm>. Acesso em 10 set 2004.

FOLHA ONLINE. homepage. São Paulo: Folha de São Paulo, 2004. Disponível em $<$ http://www.folha.com.br/>. Acesso em 12 set 2004.

FREIRE, Paulo. Pedagogia do oprimido. 13ed Rio de Janeiro: Paz e Terra, 1983. 219 p.

GOOGLE. homepage. Mountain View, CA: Google, 2004. Disponível em $<$ http://www.google.com/>. Acesso em 10 set 2004.

GOOGLE ALERT. homepage. Gibraltar, UK: Indigo Steam Technologies, 2004. Disponível em <http://www.googlealert.com/>. Acesso em 10 set 2004.

GUTIERREZ, Suzana. Filtre informações usando o RSS. Folha de São Paulo, São Paulo, caderno Informática, p. 5, 16 fev 2004. Entrevista concedida à Kátia Arima.

GUTIERREZ, Suzana. Mapeando caminhos de autoria e autonomia: a inserção das tecnologias educacionais informatizadas no trabalho de professores que cooperam em comunidades de pesquisadores. Porto Alegre: UFRGS, 2004. Dissertação (Mestrado). Programa de Pós-Graduação em Educação, Faculdade de Educação, Universidade Federal do Rio Grande do Sul, Porto Alegre, 2004. 233p. 
PROJETO ZAPT homepage. Porto Alegre: TRAMSE-UFRGS, 2003. Disponível em $<$ http://www.ufrgs.br/tramse/pzapt/>. Acesso em 05 set 2004.

RHEINGOLD, Howard. The Virtual Community. Mill Valley, Rheingold Associates, 1998. Disponível em <http://www.rheingold.com/vc/book/>. Acesso em 04 jun 2004.

RHEINGOLD, Howard. Smartmobs: The Next Social Revolution. Cambridge, MA: Perseus Publishing, 2002.

SHARPREADER. homepage. Charlotte, NC: Luke Hutteman, 2004. Disponível em $<$ http://www.sharpreader.net/>. Acesso em 10 set 2004.

THE NEW YORK TIMES. homepage. New York, NY: The New York Tomes Company, 2004. Disponível em <http://www.nytimes.com/>. Acesso em 10 set 2004.

TRAMSE homepage Porto Alegre: TRAMSE-UFRGS, 2004. Disponível em $<$ http://www.ufrgs.br/tramse/>. Acesso em 10 set 2004.

WIRED NEWS. homepage. San Francisco, CA: Lycos Inc., 2004. Disponível em $<$ http://www.nytimes.com/>. Acesso em 10 set 2004. 